\title{
Organizaciones civiles de desarrollo social y crisis en la Venezuela Bolivariana*
}

\author{
Barrantes A., César A.**
}

\section{Resumen}

El objetivo del trabajo consiste en describir las representaciones sociales que un grupo de organizaciones civiles de desarrollo social, han construido de sí mismas, y de su papel en tanto actoras políticas en lo social. El escenario visualizado es aquel que, en los tiempos de encanto de la modernidad, fue referido al pueblo y al mundo de vida popular, pero en los de transicionalidad posmoderna, viene siendo denominado sociedad civil, esfera pública, sector privado no lucrativo y economía popur lar, social, pública y/o asociativa. La investigación es de tipo exploratoria, fundamentada en documentos y entrevistas estructuradas a representantes legales y a especialistas. Se discute sobre: 1) el papel de dichas organizaciones como actoras sociopolíticas; 2) la caracterización del escenario histórico en el que se desarrollan; 3) el boom de las organizaciones no gubernamentales. Se concluye sobre: 1) la debilidad del Estado frente a la fortaleza de las organizaciones civiles de desarrollo social; 2) las cuales desarrollan estrategias de poder que permiten la incorporación de los beneficiarios en los programas en tanto consumidores de sus servicios.

Palabras clave: Organizaciones civiles, desarrollo social, Estado, ciudadanía, representaciones sociales.

\section{Civic Social Development Organizations and Crisis in the Bolivarian Venezuela}

\section{Abstract}

The objective of this paper is to describe the social representations that a group of civic social development organizations have constructed for themselves and to describe their role as political actors in the social arena. The scenario that has been visualized is one that, in times of modern social Recibido: 02-05-24 . Aceptado: 03-01-09

* Este trabajo forma parte de una investigación financiada por el Consejo de Desarrollo Científico y Humanístico de la Universidad Central de Venezuela. Mi agradecimiento a Ruth Cartaya; Leonardo Pizani; Heiber Barreto; Beatriz Bermúdez; Luis Quintana y Luis Gómez por el valioso conocimiento que se sirvieron aportar a este trabajo.

** Profesor investigador de pregrado y posgrado de la UCV y LUZ.E-mail: Cbarran@reacciun.ve. 
prosperity was referred to as a world of popular life, but in the transition to post-modernity, has been called civic society, public arena, non-lucrative private sector and popular, social, public and associative economy. This research is exploratory, based on documentation and structured interviews of legal representatives and specialists. It discusses: 1) the role of said organizations as social political actors; 2) the characterization of the historic scenario in which the activity takes place; and 3) the boom of non-governmental organizations. The conclusions are: 1) the weakness of the state in the face of strong civic social development organizations; 2 ) the development of power strategies that permit the incorporation of beneficiaries in programs as consumers of their services.

Key words: Civic social development organizations, state, citizenship, social representations.

\section{Introducción}

Nuestro objetivo es describir las representaciones sociales ${ }^{1}$ que un grupo de organizaciones civiles de desarrollo social (OCDS) -actoras sociopolíticas que vienen siendo denominadas, más por persistencia que por pertinencia por académicos, políticos y gerentes sociales, organizaciones no guberrnamentales o, simplemente, ong's-, han construido de sí mismas y de sus relaciones con la crisis del estado venezolano y la sociedad a la que él pertenece.

No obstante que nos basamos en estudios anteriores (Barrantes, 1998; 1999a), nuestra comunicación tiene un carácter exploratorio; es la razón por la cual no ofrecemos descripciones detalladas de la heterogeneidad de este singular mercado políticosocial, ni de los efectos específicos de las acciones en él realizado, tratando, más bien, de presentar una apreciación general del fenómeno que hoy ponemos en escena, sin pretender llegar a conclusiones contundentes.

Para ello, durante el primer cuatrimestre de 2002, realizamos quince entrevistas estructuradas a representantes legales de OCDS (una empresarial, cinco integradas por profesionales de clase media y nueve de promoción comunitaria) y a seis especialistas en el área.

En este artículo primero se caracteriza brevemente el escenario histórico donde se registran los eventos que le dan significado. Éste va de 1989 a 2001. En segundo lugar, damos cuenta del boom que se registra en cuanto al surgimiento de organizaciones no gubernamentales (ong's), como fenómeno político en lo social, irrumpió en el escenario nacional a

Entendemos por ellas las ideas, pensamientos, imágenes, concepciones, percepciones, visiones y nociones de los sujetos sociales acerca de sus relaciones consigo mismos, con los otros y con la realidad socialmente construida. Con Mato (2000a, 2000b) y Mora (1998) decimos que la idea tiene tres hitos bibliográficos: la formulación que en 1912 hizo Durkheim sobre las representaciones colectivas, la que en 1965 presentó Althusser, y la que Moscovici (1979) realizó en 1961. Según este último, su concepto tiene tres influencias básicas: la etnosicología de Wilhelm Wundt, el interaccionismo simbólico de George H. Mead y el concepto de Emile Durkheim. Para otra perspectiva, ver lbáñez (1996a, 1996b, 1989). 
partir de 1989. Completamos nuestro discurso con la descripción de algunas representaciones sociales acerca de la inserción realizada en los diversos niveles de la realidad nacional.

\section{El escenario de la historia}

En 1989 se produjo en Venezuela una triple coincidencia, como expresión de la crisis del estado desarrollista, bienestarista e intervencionista: el inicio del segundo gobierno de Carlos Andrés Pérez, el segundo ciclo recesivo de la mayor y más larga crisis de la economía venezolana y la fase terminal de la prolongada crisis agonal de la Cuarta República que se gestó en febrero de 1983, con motivo de la primera devaluación de la moneda nacional.

En otras palabras, el estilo rentista petrolero de resolución de problemas sistémicos y humanos del estado venezolano, había marcado la hora de su recambio hacia un nuevo modo de relacionamiento de éste con la sociedad a la que pertenece. En consecuencia, la clase política se vio concitada a aceptar que el ensayo democrático y el sistema jurídico, político construido a partir del 23 enero de 1958, el Pacto de Punto Fijo, suscrito en 1961 por los partidos mayoritarios y el modelo industrial basado en la sustitución de importaciones y la renta petrolera, habían caducado y que sus promesas de bienestar y democracia se habían desvanecido tras varias décadas de ilusión de armonía.

Los rasgos más resaltantes del escenario nacional eran, esquemáticamente, los siguientes:
1. La pugnacidad, agudizada por la larga crisis estructural iniciada en febrero de 1983, entre las fracciones de la clase política había llevado a una situación de poder precariamente compartido, de manera tal que cada una de aquéllas sólo tenía el poder para obstaculizar la gestión de sus oponentes.

2. Los actores políticos, empresariales, partidistas, sindicalistas, burocratistas y tecnocratistas estatales y civiles de diverso nivel, continuaban pugnando por preservar los términos del intercambio puntofijista como si la sociedad aún fuera la misma de treinta años atrás. En este sentido, la otrora fabulosa renta petrolera seguía siendo considerada como inagotable cornucopia de la que todos -gobernantes y gobernados, dominantes y dominados-, unos más otros menos, querían seguir extrayendo y distribuyendo, directa 0 mediadamente, legal mas no siempre legítimamente, gratificaciones tangibles e intangibles sin que éstas dejaran de seguir ilusoriamente goteando paternalista y clientelarmente hacia las clases medias y populares.

3. La ausencia de una voluntad de fortalecimiento y autonomización de la sociedad civil, correlacionaba con la persistencia de la clase política de seguir ejerciendo el poder, al margen de todo compromiso ético-político, es decir, más por el peso de sus maquinarias electorales, la maniobra cortoplacista, la concertación cupular y el acuerdo a puerta cerrada que por la transparencia testimonial, la legitimidad y la representatividad popular de sus líderes. 
4. De espaldas al aumento de las frustraciones que las grandes mayorías populares venían acumulando desde hacía varios años, las organizaciones corporativas (partidos, sindicatos, e mpresarios), desvinculadas de la representatividad colectiva, continuaban pugnando por seguir siendo los exclusivos canales de participación controlada y de asignación de identidades y gratificaciones funcionales a una política populista y clientelar de masas, en condiciones estructurales en que el Estado ya no tenía capacidad financiera para seguir activando los mecanismos de concertación tutelada (asiste ncialistas) hacia abajo y proteccionistas hacia arriba).

5. Las tendencias dinámicas que podían preanunciar avances sustantivos hacia la definición de un nuevo patrón de acumulación y de un nuevo estilo de desarrollo capitalista, así como las que podían potenciar la construcción de un sistema hegemónico nacional, democrático, activamente participativo y justo, se encontraban bloqueadas.

6. El reconocimiento de la anterior realidad, determinó que el gobierno de Pérez, a contrapelo de la propaganda electoral del año anterior, implantara el programa económico de ajuste estructural (PAE) que llegó a conocerse como el tristemente célebre paquete neoliberal. Éste tuvo como meta flexibilizar, bajo el liderazgo del gran empresariado privado y el capital trasnacional, la economía, privatizar las empresas estatales y, supuestamente por esta vía, abrir de manera irreversible, la sociedad venezolana a la competencia de los mercados internacionales globalizados.

La realidad demostró que los supuestos y el cálculo que se desprendió de ellos fueron erróneos. Al contrario de lo esperado por la clase política, los tecnócratas y políticos de turno, con la puesta en marcha del PAE, lejos de recuperar la bonanza consumista perdida durante el decenio anterior, se inauguró la fase terminal de la Cuarta República, cuyo desenlace final fue su desplome electoral en diciembre de 1998.

Los síntomas perversos de dicha fase terminal, fueron los siguientes: el deterioro progresivo de la calidad de vida de la población, el incremento de los índices de la pobreza, la turbulencia políticosocial, la protesta popular (Bisbal y Nicodemo, 1992; López Maya, 1999a), el aumento de la represión policiacomilitar, el incremento abrupto y exacerbado de la complejidad societal, la imprevisibilidad institucional, la deslegitimación del sistema político y la ingobernabilidad (López, 1999b:211-238; Salamanca, 1999:239264; Gómez, 1995:103-164); asimismo, la estanflación, la corrupción político-administrativa, la impunidad y la inseguridad individual, social, pública, alimentaria y jurídica y el desencanto generalizado por las promesas que no cumplió el proyecto modernizador de factura socialdemócratacristiana ni la democracia representativa, tal como se practicó en Venezuela entre 1958 y 1998.

El desplome del régimen puntofijista a los cuarenta años de su instauración, se vio significado por la abrumadora victoria electoral de Hugo Chávez Frías en diciembre de 1998. Este hecho marcó la 
puesta en marcha de un largo, enconado y difícil proceso de regeneración del cuerpo social, de facultamiento de las instancias estatales y civiles formales e informales, de reconfiguración del sistema político y de reconstitución de las identidades de los actores sociales, políticos, económicos y culturales sobre la base del protagonismo ciudadano. Pero, fundamentalmente, ha significado la fragua $y$ revaloración del estado nacional como estado integral socialmente centrado y la construcción de nuevas representaciones sociales sobre la nacionalidad y la sociedad considerada esta última en su conjunto más inclusivo y a la cual pertenecen tanto el estado venezolano como las actoras estudiadas.

Proceso que está pasando por la necesaria puesta en marcha de una necesaria tendencia -esperamos transitoria- a la centralización político-administrativa, cuyo efecto más inmediato, nos parece, es la desaceleración de los efectos desintegradores provocados tanto por la crisis terminal del régimen puntofijista como por la tardía reforma formal del estado venezolano, tal cual se comenzó a practicar con más contramarchas que marchas, durante el último decenio del siglo pasado.

Sin embargo, la Quinta República no puede considerarse más que en incipiente proceso de consolidación, en especial si consideramos que el viejo sistema de relaciones sociales, de hondas raíces ideológico-culturales en la historia venezolana, se resiste a ser olvidado y continúa prolongándose desde el pasado reciente y profundo, y en cuyo ínterin se viene suscitando una constelación de síntomas morbosos y anómicos pletóri- cos de turbulencias y entropías, a veces insospechadas.

\section{Las organizaciones civiles de desarrollo social}

Al contrario de otros países, en Venezuela aún no contamos con una legislación única sobre OCDS, aunque sí existen regulaciones específicas para organizaciones, tales como: Cooperativas, partidos políticos, iglesias, sindicatos, asociaciones de vecinos, fundaciones y corporaciones, cuyos controles dependen del poder judicial y no del poder ejecutivo.

Dichas normas son a veces inconexas, heterónomas y ambiguas en virtud de que se encuentran dispersas en una diversidad de decretos y leyes que no han sido puestos a tono con la Constitución de 1999, expresando en algunos casos la desconfianza miope de los legisladores del régimen anterior (González, 1998: 25), lo cual, sumado a la inexistencia de un registro único, de estímulos tributarios y controles en el procedimiento de la legalización, son factores que no contribuyen a la transparencia del aglomerado de OCDS.

En nuestro país el conocimiento de éstas es aún incipiente, razón por la que sólo existen directorios y listas parciales en entidades civiles y oficiales, algunos de los cuales mantienen convenios con aquéllas.

Asimismo, existen sólo seis estudios exploratorios realizados con muestras pequeñas y estudios de casos referidos a áreas específicas (Cartaya, 1993; Navarro, 1994; García y Roa, 1997; Machado, 1997; Cisor, 1997a; Barrantes, 1998, 1999). Significando un avance en cuanto a la cobertura de las mismas, con- 
tamos tres estudios clasificatorios por actividad, realizados con muestras nacionales: Cisor (1997b) con 1.116, Socsal (1998) con 1.007, y González (1998) con 24.628 organizaciones.

En algunos aspectos la historia de las OCDS se ha entreverado, marginal y casuísticamente, al desarrollo del sistema político, del movimiento popular y de la sociedad en general (López, 1984, 1999a; Lander, 1995a, 1995b; García y Roa, 1997).

La ausencia de estudios ha conducido a afirmaciones equívocas, tales como que las OCDS son un fenómeno propiamente democrático-representativo y, más específicamente, de la crisis terminal de la Cuarta República (Navarro, 1994; Machado, 1997).

Al denominarlas OCDS (Barrantes, 1998) e integrarlas -conjuntamente con las organizaciones gubernamentales de desarrollo social (OGDS)- en la categoría genérica de organizaciones de desarrollo social (ODS), compartimos la opinión de diversos autores (Lander, 1995a; Bejarano, 1996:113-144) de que la denominación no-gubernamental ostenta un sentido negativo en tanto define a aquéllas por lo que no son. Según una opinión generalizada en algunos sectores académicos, gerenciales y políticos, las denominadas ong's son no oficiales, no corruptibles, no burocráticas, no opresivas y no ineficientes; ello en magnificado antagonismo con el supuesto carácter genéticamente ineficiente, burocrático, opresor y corruptible de los aparatos político-administrativos a los que es reducido el estado venezolano.

"...las ong's por ser privadas son buenas y tienen todas las virtudes de la democracia, y el estado y los partidos siempre son malos y corruptos...".

Asimismo, el término sin fines de lucro significa que, a diferencia de la empresa privada, el desiderato de las OCDS no es la ganancia económica; sin embargo, los juegos lingüísticos de muchos miembros de ong's magnifican su afinidad con la racionalidad empresarial, en virtud de lo cual las inversiones sociales realizadas por aquéllas son consideradas, si bien sin fines de lucro, fundamentalmente sin fines de pérdida ${ }^{2}$.

A diferencia de los nombres con que se les identifica, el de OCDS expresa un sentido proactivo, porque las define ya no por lo que no son, sino, por lo que son en referencia a su ámbito constituyente: la sociedad civil, y a un concepto genérico de desarrollo social y de promoción del bienestar individual-colectivo de la población.

Un ejemplo de eficiencia programática y de acumulación económica tomado de Barrantes (1999), es el Banco para la Gente Emprendedora (Bangente). Éste es la cristalización más importante de la asociación estratégica liderada por el Grupo Social Cesap a través del Grupo Sinergia, integrada por representantes de la Fundación Mendoza, la Fundación para la Vivienda Popular y el Centro Empresarial "Fundes-Venezuela" con la asistencia financiera de la Corporación Andina de Fomento, la Fundación Internacional Gateway, Profund International, el Banco del Caribe y el Fondo Multilateral de Inversiones del Banco Interamericano de Desarrollo. El capital accionario inicial de esta empresa financiera fue de Bs. 1.200.000.000 en 1998. 


\subsection{Las OCDS como actoras políticosociales}

Las OCDS son actoras políticas en lo social; muchas de ellas noveles e influyentes protagonistas de la búsqueda institucional de satisfactores de una constelación de situaciones carenciales que afectan a individuos, familias y organizaciones.

"Claro que son actoras políticas; que no lo quieran reconocer es otra cosa. Que se hayan querido erigir en agentes apartidistas y apolíticas es otra cosa, pero incluso esas que se erigen en sociedad civil pura, impoluta y desideologizada le hacen un gran juego al neoliberalismo, aunque prediquen lo contrario. Lo que pasa es que eso ha sido parte de la antipolítica, un discurso apolítico para hacer juego político...".

Su presencia pública -que ya venían teniendo desde décadas anteriores, aunque de manera silenciosa 0 , al menos, no difundida por medios masivosadquirió sentido en el marco de la crisis terminal de la Cuarta República. Es lo que conocemos como el boom de las ong's, cuya notoriedad se vio publificada -gracias al cabildeo comunicacional de muchas de ellas- por los medios de difusión masiva, que magnificaron sus capacidades de gerenciamiento, autonomía antiestatal, civilidad, democratismo, eficiencia, flexibilidad organizacional y diversidad de servicios prestados en una multiplicidad de ámbitos ${ }^{3}$.
Dicho boom, ha llevado a una idea equívoca que reduce la sociedad civil a las denominadas ong's, que son conocidas en virtud de sus posibilidades de acceso a los medios de difusión masiva, tal es la representación social del gerente de una OCDS empresarial:

"La gente piensa que sociedad civil son las ong's que conocen, la sociedad civil también tiene muchas otras formas de expresión, por ejemplo, en Venezuela hay 240 cooperativas que dan créditos a microempresas, y no las conoce nadie, y están vivas y trabajando, bueno, 240 familias, no pagan páginas en el periódico, pero son sociedad civil organizada".

Con esta base mediática -reforzada por la relevancia adquirida por algunas asociaciones civiles, especialmente de clases media y alta (Lander, 1995a; García y Roa, 1997) que siguen ostentando alto honor social y autonomía financiera-, las OCDS advinieron al escenario nacional autorreputadas como intermediadoras eficientes, transparentes e impolutas entre el Estado y la sociedad civil.

Lo anterior, mediado por actores globales multilaterales y bilaterales, gubernamentales y privados, pero fundamentalmente por la oferta estatal de créditos blandos y por la convocatoria apresurada y selectiva que, a comienzos de 1990, presentada a las OCDS más experimentadas, exitosas y mayormente conocidas por el funcionariado oficial, a los efectos de que se incorporaran en calidad de operadoras del proceso social de produc- 
ción, distribución y consumo -ampliado por el incremento abrupto de la demanda popular provocada por el ajuste estructural- de los valores de cambio y de uso objeto del conjunto descoordinado de programas asistenciales, compensatorios y focalizados a los que fue reducida la política social hasta 1999 (Carvallo, 1999; Pulido, 1999; Barrantes, 1997: 101-123; González, 1997) ${ }^{4}$.

Dicha convocatoria se vio determinada por una tríada de sucesos de diverso nivel:

1. La ofensiva neoliberal y sus propuestas de desmantelamiento del intervensionismo del estado desarrollista latinoamericano $\mathrm{y}$, particularmente, venezolano que ya se mostraba insoslayablemente discapacitado para satisfacer las necesidades básicas de amplios agrupamientos poblacionales.

2. El optimismo generado por la elección uninominal de gobernadores y alcaldes en dicie mbre de 1989: la única cristalización tardía -lograda con el concurso de diversos actores socia- les entre los cuales se contó un grupo de organizaciones vecinales de clase media- del proceso de decentralización político-administrativa del estado venezolano decretado en 1984.

3. Pero fundamentalmente, por la abrupta implosión del sistema político-económico, producida por la deslegitimación y discapacidad de gobernación de la clase política, cuya dramática manifestación fue la rebelión popular conocida como El Caracazo, la cual fue sangrientamente reprimida por las fuerzas policíaco-militares entre el 27 de febrero y el 3 de marzo de 1989.

Este hito marcó el inicio de la crisis terminal de la Cuarta República. En consecuencia, el Estado intentó, pesadamente y a marcha forzada, reconducir sus relaciones consigo mismo, con el sistema político, la nación, la sociedad civil y con sus propias instituciones. En consecuencia, los heterogéneos y contradictorios significados de su otrora imperativo e indiscutido papel de satisfactor diferencial de carencias y aspiraciones, comenzaron a ser delegados

y ciencia elitescas; economía y política liberales y vida vecinal especialmente de clase media profesional; administración de justicia, penitenciarismo y justicia de paz; inversión en infraestructura física (obras colectivas, comunitarias) y en capital social (promocionales, sociorganizacionales e instruccionales, asistencia jurídica, crediticia y tecnológica, gestión local) y humano (educación, salud, alimentación, vivienda); defensa de derechos (animales, ambientales, humanos).

4 Dichas áreas eran salud, educación, alimentos estratégicos, animación sociocultural, asistencia y rehabilitación social, crediticia y técnica a microempresas y ferias de consumo populares, tanto como la administración de los hogares infantiles de cuidado diario y la promoción de la inserción laboral de los jóvenes excluidos por el sistema educativo. Según Socsal (1998), la concentración de actividades de las ong's era la siguiente: educación (21\%); salud (14,2\%); apoyo al desarrollo (14\%); cultura y arte (10,3\%); deporte y recreación ( $8 \%)$; generación de ingresos $(7,3 \%)$; derechos civiles $(6,2 \%)$; medio ambiente $(5,9 \%)$; servicios básicos e infraestructura(5\%); religión (4,6\%); ciencia y tecnología (3,8\%). Para Tabúas (1995), "La mayor parte de las ongs...se dedican a la educación (21\%), infancia y juventud (18\%) y economía popular (15\%), justamente...tres áreas críticas del país". 
-parcialmente y tras una cadena de marchas y contramarchas, encuentros y desencuentros- en OCDS ${ }^{5}$.

Lo anterior no implicó la posibilidad -quizá porque, como se deriva de Barrantes (1998), no lo percibieron como necesidad o porque ésta se vio mediatizada por discapacidades, ambivalencias y desconfianzas mutuas durante el decenio pasado- de que tanto éstas como aquéllas realizaran un trabajo asociado con derecho a coparticipar en las instancias decisorias oficiales y en el rendimiento de cuentas mutuas; tampoco significó que las OCDS se decentraran a sí mismas ni que dieran rienda suelta al poder de sus beneficiarios, de forma tal que éstos pudieran apropiarse de sus derechos ciudadanos en la práctica misma de su participación activa en la gestión, control y evaluación de los servicios recibidos ${ }^{6}$.

"En Barquisimeto cuando los beneficiarios...quieren compartir la administración de los recursos, la ong's intermediaria los frena y les dice 'la participación es para que me reciban la arepa, no para que se metan en el programa que está a mi cargo'. Se repite el patrón vertical al que estamos acostumbrados".

"Dada las normativas crediticias de las ocds...éstas coartan (a) los (beneficiarios), ya que estos no pueden participar directamente en la administración de los recursos".

En la actualidad, según se desprende de las representaciones sociales anteriores, esta situación parece no haber variado aunque las relaciones de las OCDS con el Estado se encuentran atravesando un periodo de nuevos alejamientos y desencuentros, como veremos más adelante.

\subsection{La macroesfera pública}

Como ya mencionamos, la implosión del sistema político y la retracción política y financiera del estado venezolano a partir de 1989 , dejaron a la intemperie un ancho y profundo campo que algunas OCDS comenzaron a llamar lo público -a veces adjetivado de no estatal o ci-

5 También en OCDS, pero de ellas no daremos cuenta por no formar parte de nuestro objetivo. Sólo diremos que los institutos y corporaciones autónomas, los gobiernos estadales y locales y las fundaciones y corporaciones adscritas a ministerios, gobernaciones y alcaldías, no siempre estuvieron en capacidad de asumir la transferencia de competencias ni de administrar con eficiencia y eficacia los pocos programas delegados por el poder central, y que sus propias debilidades fueron un factor que no les permitió llegar a experimentar procesos reales de decentramiento de su matriz estadocéntrica, de dotación de dispositivos estratégicos y operativos, ético-políticos (dispositivos de deliberación, consulta y codecisión despartidizada) y tecnológicos ni del deseo del otro, a fin habilitarse en la práctica misma de ir al encuentro de los sujetos que encarnan la sociedad venezolana (ver Barrantes, 1997).

6 Una de las muchas tensiones semánticas de las representaciones sociales de las OCDS señaladas por Cisor (1997a, 33), es la de que, por un lado, éstas "mantienen relaciones paternalistas con la población (y) acapara(n) los recursos y el know how. Así aseguran el mercado y mantienen cautivos a los clientes" y, por otro, "reivindican el derecho de la población a ser actor (sic) o a moldear la oferta de bienes y servicios..." 
vil- pero también tercer sector de la economía y sector de economía social, popular, solidaria o pública; asimismo, sector de ong's, polo asociativo y, siguiendo la nomenclatura norteamericana y los razonamientos económicos aplicados a lo social, sector privado no lucrativo (Cisor, 1997a; González, 1998).

Mediante dicho campo, los partidos políticos y sus cúpulas de poder a las que grupos empresariales, sindicales, eclesiales, militares y académicos no eran totalmente ajenos, habían construido los complejos entramados de sus relaciones clientelares, populistas y corporatistas con la sociedad venezolana. Escapando a los controles de la justicia y la democracia, instauraron lo que en los años de mayor auge e impunidad de la corrupción político-administrativa, se dio en llamar los entornos íntimos del estado venezolano.

"Como decía Cabrujas, Venezuela es un campamento donde la institucionalidad es muy débil, la burocracia es según convenga y cada quien quiere extraer lo que más pueda....al final la ministra es comadre mía...los personalismos funcionan también cuando vas a un periódico o a una industria...".
Se trataba, pues, de una virtual tierra de nadie cuyo costo de oportunidad más relevante era, en palabras de uno de los especialistas en OCDS entrevistados, la "liberación de la sociedad civil, la economía y la política de la intervención del Estado" mediante la iniciativa privada y, por esta vía, constituir a aquella en una promisoria tierra de todos los venezolanos dentro de la que se destacaría el mercado jurídicamente liberado, pero en especial la noción del trabajo social corporativamente organizado ${ }^{7}$, fundamento del liderazgo gerencial y políticosocial de las OCDS.

"Las ong's somos una especie de trabajadoras sociales corporativas bajo las condiciones que están planteadas en Venezuela".

Es así que éstas se constituyen en empresas sociales de alta productividad: si bien sin fines de lucro, fundamentalmente sin fines de pérdida, lo que equivale a no descuidar en modo alguno, la capacidad de acumulación y reinversión: condición sine qua non de su desiderato de autonomización financiera del Estado, mas no necesariamente de las entidades privadas extranjeras y multilaterales.

Para quienes no son trabajadores sociales, este término se refiere a la actividad no profesional que se realiza para beneficio de los vulnerados por los altibajos de la tasa de ganancia. En la lógica de esta representación social, dicha actividad es gratuita porque quienes se dedican a ellas cuentan con rentas propias, son asalariados del Estado o militantes de religiones. El adjetivo corporativo introduce un sentido distinto que se refiere siempre al tiempo que se dedica a beneficiar al prójimo, pero esta vez gracias a la iniciativa privada de cada emprendedor individual y colectivo -vgr. las OCDS- en virtud de lo cual se debe obtener una rentabilidad social o ganancia mínima que permita recuperar los recursos invertidos o, mejor, acumular fondos de trabajo cuando no capitalizar con el afán de financiar alianzas estratégicas, nuevos proyectos y la ampliación de las coberturas de los existentes. 
En virtud de lo anterior, algunos de nuestros cooperantes coinciden con uno de los especialistas entrevistados, en la representación social según la cual el escenario posible para las OCDS, en especial las de mayor tamaño, antigüedad y autonomía financiera, era el de que:

"...conforme el Estado venezolano evidenciara su incapacidad para satisfacer las crecientes demandas sociales, ellas irían posicionándose de espacios y sembrando en ellos su función de utilidad social; asimismo, poniendo a prueba su naturaleza gerencial, podrían ir asumiendo las funciones de bienestar, desarrollo y asistencia social que el Estado y sus instituciones ya no podrían cumplir por sí mismos".

En esta última concepción, lo público ya no es un problema de gasto social, que realizado a fondo perdido, morigera y, eventualmente, mejora la situación social de los pobres al margen de toda potenciación del consumo productivo y de la producción de ciudadanía, sino un sector abierto a los emprendimientos sociales y a las iniciativas privadas (individuales y empresariales), lo cual implica la transformación semántica del asistencialismo en inversiones productivas al servicio del incremento cualitativo de la situación económica de la ciudadanía consumidora, abriéndole nuevas fronteras al mercado $y$, por ende, a las inversiones del capital.
"Para algunas ong's, la prestación de servicios dejaba de ser un fin en sí mismo para constituirse en instrumento de un proyecto -más bien diríamos de un imaginario político- de organización social caracterizable por un estado mínimo, un expansivo sector privado no lucrativo, un dinámico sector económico productivo y un mercado que permitiera realizar la motivación al logro y la ciudadanización de cada quien".

Con esta representación social, coincidente en varios sentidos con las de otros cooperantes, uno de los especialistas entrevistados introdujo el verdadero significante del trabajo social corporativo realizado por las OCDS: lo político, pero no en el sentido fuerte de los partidos políticos y la lucha por el poder del Esta$\mathrm{do}^{8}$, sino en el de la gestión articulatoria de los mundos de vida, de la satisfacción de necesidades sociales y de la construcción de identidades al horizonte normativo de la globalización, cuyo punto de llegada es el mismo que el de partida: la sociedad liberal industrial y su valor esencial: el individualismo competitivo ${ }^{9}$.

\subsection{Estrategias de posicionamiento}

Los posicionamientos que las OCDS han realizado en la macroesfera pública -conjunto de campos significados por la política en tanto carácter profundo

Sentido que no es estático en modo alguno, pues no siempre se sabe a ciencia cierta cómo, dónde y cuándo la mediación deriva en mediatización, el condicionamiento en determinación, el fenómeno en esencia, la connotación en denotación y viceversa, de manera tal que no siempre es fácil diferenciar matices, especialmente en zonas multifronterizas inestables entre lo social, lo económico, lo cultural, lo político, la política, entre otros, (sobre la relación Estado-sociedad civil, lo público y lo privado y amplias referencias al papel de las OCDS, (Cunill, 1995, 1997); Magallanes (1995, 1997); García Guadilla y Roa (1997); Machado (1997). 
de la sociedad civil-, se han visto mediatizados por varias razones; entre éstas las siguientes:

1. El temor a las tentaciones autoritarias y corporatistas ha concitado a algunas a representarse a sí mismas como exclusivamente técnicas, administrativas, profesionales, y apolíticas en el sentido de apartidismo y neutralidad respecto de la lucha política realizada por los actores fundamentales interesados en detentar los poderes del Estado.

2. Los dispositivos político-estratégicos con que algunas se han dotado, las asemeja a grupos de presión que se fundan en la práctica del cabildeo y las relaciones de influencia.

3. La orientación al trabajo social corporativo, es decir, la venta de sus servicios, las compulsa a la dependencia de fuentes de financiamiento especialmente privado nacional, internacional y multilateral, a la adopción de criterios de eficiencia en el uso de sus recursos escasos y a la búsqueda de clientelas con capacidad de pago.

"Es importante no partidizar...sí politizar la práctica social de las OCDS, (para) la comprensión de la necesidad de generar sus propias formas de poder y conquistar no el poder, sino, poderes en plural (capacidades, facultades), y de darse cuenta de que el poder no es cochi- no per sé, prurito convertido en discurso maniqueo en la última década...".

"(Como) las trasnacionales, grandes empresas, grandes bancos,...no nos metemos en la política chiquita...nuestra ong es muy profesional. Tenemos posiciones muy claras y determinantes. Los modelos de desarrollo sostenible implican posiciones de principios, forman parte de nuestra misión. Pero no participamos de la política diaria".

De las representaciones anteriores podemos deducir que las OCDS en su mayoría no se encuentran partidizadas, no obstante que muchas de ellas se sienten identificadas con doctrinas y prácticas de partidos políticos que, en determinados momentos, asumen y defienden. Esto no significa que no tengan una imagen-objetivo de su propio desempeño histórico, ya que mediante estrategias de posicionamiento han ganado poder no siempre ajeno a los intereses partidistas y mediáticos.

Podemos ver, por ejemplo, que una ong: Primero Justicia, constituyó el partido político de su mismo nombre, al igual que otras fundan empresas económicas y consorcios financieros en cuya asamblea de socios gravitan, al menos, los miembros de mayor influencia de las OCDS de que se trate. Claro está, considerando que la misión principal de éstas no es partidizarse, economizarse, empre-

“...entre nuestras estudiadas no se evidencia una concepción de política en el sentido de la transformación de las estructuras societales, las movilizaciones masivas y la satisfacción de necesidades colectivas tal como se entendía en los decenios sesenta y setenta, sino una noción de política light resemenatizada por (el) discurso economicista, financista y tecnocrático" (Barrantes, 1998: 30). 
sarializarse o comercializarse, sino, prestar servicios que tiendan a autonomizar y facultar a los sujetos de carencias.

"...Política en el sentido del sistema político la hacemos mal como ong's, porque la misión no es esa, aunque algunas están haciendo política partidaria, como Primero Justicia..., pero ésta no creo que marca lo que debe ser la ruta de la sociedad civil organizada."

"Los partidos son esenciales, pero su papel no lo veo para las ong's. No lo saben hacer, no están hechas para eso. Cuando se salen de lo técnico y apuntan a lo ideológico-político, pierden los papeles".

"La (inexistencia de) una oposición política nacional, ha llevado a algunas a jugar un papel que no les corresponde. Ellas no son oposición política, aunque defiendan lo que piensan que el gobierno les está quitando...".

Según lo anterior, la racionalidad de los regímenes económico y de partidos es considerada como ajena a la naturaleza de las OCDS -en especial de las que se autorreputan como técnicas, profesionales, apolíticas y apartidistas- ello no significa que su participación en la lucha por los poderes del Estado sea un deseo que efectivamente algunas prefieran reprimir, en especial en estos tiempos cuando el sistema político se encuentra pulverizado y la tentación autoritaria está a flor de piel de algunos sectores sociales. Tampoco implica que su contribución al incremento general de la tasa de ganancia no pueda ser realizada de manera indirecta, pues jurídicamente están facultadas para crear todo tipo de entidades (partidos y empresas inclusive) lícitas a fin de asegurar el cumplimiento de sus desideratos. “...algunas se han convertido en consorcios que ellas mismas denominan ong's cúpula o paraguas porque cobijan a decenas o centenas de otras ong's".

\subsection{La producción de ciudadanía}

De acuerdo con los pocos estudios realizados en el país sobre OCDS, podemos afirmar que éstas se nos vienen presentando -dentro del marco de la Constitución de 1999, de un régimen sociopolítico y económico enrarecido por la pulverización de los partidos políticos especialmente de oposición, de nuevas concepciones de política social y nuevos protagonismos ciudadanos- como prestadoras de servicios de capacitación y asistencia social, rehabilitatoria, técnica y crediticia y como operadoras de un modelo específico de política social: el compensatorio y focalizado propio del Estado rentista-bienestarista-asistencialista en su momento de crisis agonal.

Es la razón por la cual las acciones programáticas de aquéllas, parecen expresar una tensión semántica entre los procesos de facultamiento social o construcción de poderes autonómicos de base, implicados en la ciudadanización de la macroesfera pública, y el lenguaje según el cual ésta es reducida a un virtual sector social privado no lucrativo cuyas actoras privilegiadas son las denominadas ong's de mayor solvencia económica y mediática.

Un ejemplo de lo anterior, es el hecho de que cuando llegó el momento de la firma de los convenios financieros a partir de 1990, aquéllas -en especial la mayoría que no tenía experiencia en el ámbito de la cooperación nacional e internacional y cuya única fuente de fina nciamiento pasó 
a provenir del Estado ${ }^{10}$ - se vieron concitadas a instaurar dispositivos de control de gestión física y financiera, tendientes a satisfacer más los términos contractuales con los prestamistas oficiales, privados, extranjeros y multilaterales que las necesidades de ciudadanización de los usuarios de sus servicios.

Ahora bien, en referencia a las representaciones sociales de las OCDS, pareciera que la producción de ciudadanía es considerada una portentosa tarea que le corresponde al Estado integral-nacional o, lo que es lo mismo, a la sociedad venezolana considerada en su conjunto más inclusivo.

"La producción de ciudadanía...se tiene que gestar desde una educación familiar y escolar integral y con una política sociocultural dirigida a la sociedad civil, donde el venezolano adquiera, defina y revalore su identidad y su sentido de pertenencia".

Es así que las OCDS son -apenasunas de las tantas actoras involucradas que, por lo demás, ostentan como su mayor debilidad la dependencia financiera, lo cual incide directamente en su baja efectividad para influir, de manera decisiva y sin los condicionamientos de los prestamistas ni los determinismos de su propia sobrevivencia, en los diversos momentos del proceso de ciudadanización de la macroesfera pública.
"Muchas ong's han contribuido a crear ciudadanías barriales y comunitarias, ciudadanos de segunda y sujetos de necesidad que no se constituyen en sujetos de derecho y de justicia, pues con paliativos no se construyen articulaciones con la venezolanidad".

"Es un proceso largo que no les corresponde plenamente pero tienen que hacerlo; no todas lo han hecho bien...considerando su imagen de eficiencia y experticia".

En este sentido, las representaciones sociales de nuestros cooperantes nos permiten afirmar que, en esta larga agonía transicional no resuelta, las OCDS no han dado muestras de estar habilitadas para decentrarse a sí mismas, ir al encuentro del Estado y dotarse de mecanismos participatorios, de forma tal que sus respectivas poblaciones cautivas puedan tener posibilidad de, al menos, opinar sobre la oferta de bienes y servicios de aquéllas.

"Algunas son muy verticales con su clientela, llevándoles una ayuda, un crédito, una arepa o una casa; (los clientes) se asumen como beneficiados (a quienes) les está dando una dádiva alguna ong buena que incluso catequiza con los recursos del Estado. Esto es reforzar la anticiudadanía, el mesianismo, la docilidad".

10 La noción de política de las OCDS "se ve expresada en las estrategias de sobrevivencia desplegadas por la gran mayoría (cuya) condición vital (es) la búsqueda compulsiva de fuentes de financiamiento,...la adopción de criterios de eficiencia ("antes que servir tenemos que sobrevivir para poder servir") en el uso de sus recursos escasos y...la práctica del cabildeo o lobbysmo público y privado" Barrantes (1998:30). 
"Le exigen al Estado y a los partidos democracia, transparencia y deferencia, pero muchas no son democráticas ni transparentes ni creen en partidos, aunque más de una quiere serlo".

Pareciera derivarse de las representaciones hasta aquí transcritas, un acotamiento acorde con el discurso político e ideológico hegemónico venezolano, según el cual la sociedad civil es lo que no pertenece al Estado ni a lo popular, sino a las clases que, siendo portadoras de civilidad, modernidad y conocimiento tecnocientífico, se desidentifican de la supuesta barbarie e incivilidad que caracterizan a los amplios agrupamientos sociales que integran la categoría pueblo.

"Yo no soy muy optimista en el papel que juegan las ong's en el corto plazo...no las veo organizándose como movimiento social...de clase media, mucho menos de carácter popular. No veo posible que se organicen como contrapeso al poder absoluto y centralizador...dado el proceso de fragmentación instaurado desde hace años...".

En consecuencia, en el discurso de algunos sectores de OCDS pareciera estar implicada la diferenciación y toma de distancia respecto de las organizaciones populares o de base, lo cual tiene sentido en especial si consideramos que, desde hace varios lustros, lo popular viene siendo política e ideológicamente devaluado y desconceptualizado, en virtud de que al pueblo se le asignan como rasgos exclusivos los propios de la cultura política venezolana, de la cual las OCDS son también usufructuarias para bien o para mal: el clientelismo, el paternalismo, el populismo y el rentismo.
Lo anterior no ha sido obstáculo para considerar a las organizaciones populares como objeto natural de la intermediación y mercado social para el consumo de los servicios de las OCDS.

"La pluralidad (nos) permite el debate y la inserción en realidades comunitarias concretas: las de sus organizaciones y sus representantes, porque no queremos replicar a las ong's, que son una implicación muy superficial en la realidad que intentan intermediar".

(Mantenemos la) condición de igual con las organizaciones populares; no las vemos como beneficiarias, clientes u objetos utilitarios porque...nos enriquecemos mutuamente respetando la diferencia de roles".

Sin embargo, las representaciones sociales anteriores apuntan a señalar una diferencia sustantiva en la actual relación OCDS-organizaciones populares con respecto a la práctica del decenio de los noventa: la horizontalidad respetuosa de las diferencias entre actoras sociales que tienen como misión diferencial la constitución de sujetos ciudadanos, autonómicos y democráticos.

\subsection{Relación con el Estado}

La relación del Estado con sectores importantes de OCDS durante la fase terminal de la Cuarta República, no siempre fue transparente ni plenamente satisfactoria; más bien, ateniéndonos a diversas investigaciones, fue tensa, ambigua, asincrónica, ambivalente y signada por desencuentros y sospechas mutuas (García, 1991; Navarro, 1994; Lander, 1995a, 1995b; Machado, 1997; Cisor, 1997a; García y Roa, 1997; Barrantes, 1998, 1999). 
Así lo testimonian las representaciones sociales de dos directivos de OCS populares de Caracas y Barquisimeto:

"Durante CAP II, les faltó asertividad para relacionarse con el Estado y más de una abusó de su buena fe en el ámbito de las microempresas y las ferias de consumo popular...Caldera optó por buscar otro tipo de organizaciones...que tuvieran un perfil distinto a las ong's...más confiables y funcionales a la política establecida por el partido oficial...".

"...el ministro de la Familia de Caldera II temía darle importancia a las casi mil ong's con las que mantenía convenio para administrar los hogares de cuidado diario; temía que se le sindicalizaran y pusieran contra la pared al gobierno...no era una relación de socios, sino utilitaria...y en muchos casos desleal con el Estado".

Como matiz del sentido anterior, la representación social construida por otros cooperantes es que durante los noventa, un número considerable de OCDS se sujetó de manera ambivalente a la política oficial, perdiendo de vista sus objetivos primigenios, en especial los cientos que fueron creadas por partidos, organismos oficiales y allegados a los entornos íntimos de los gobiernos, con el afán de captar recursos, evadir impuestos y abaratar los costos de sus actividades empresariales.

"Para obtener financiamiento dejaron de lado sus objetivos y aceptaron las pautas de los gobiernos, perdiendo autonomía..."

"Muchas no se crearon (para) beneficio de la población, sino totalmente lucrativas, cayendo en actos de corrupción".
En cuanto a las discapacidades del Estado venezolano, algunas representaciones sociales apuntan a significarlas como síntomas de la desaparición o minimalización de aquél y como señal de que la hora de la sociedad civil -ya autonomizada de la política al influjo de las fuerzas del mercado- había llegado y, con ella, la virtual hegemonía de las ong's tecnoexpansiva a la cual debían ser integrados, tanto el Estado como los agrupamientos populares.

En este sentido, varios entrevistados coinciden en la representación social de que algunos sectores de OCDS, adoptaron estrategias de incremento de sus variables de libertad poniendo más énfasis en las debilidades del Estado que en las fortalezas de sí mismas, lo cual las llevó a magnificar el poder corruptor y opresor de aquél y a ocultar sus propias debilidades e intereses particulares.

"Se sintieron fuertes frente a las debilidades del estado y muchas ong's quisieron aprovecharse de la oportunidad...para trabajar en función de su interés particular de hacer girar toda la sociedad alrededor de sus propios valores, de la globalización y de la clase media..."

"...desconcientizaron que hay muchas ong's que son tan o más corruptas, ineficientes y explotadoras que el Estado y los empresarios, e incluso las mas importantes...se transformaron en máquinas de hacer dinero".

En contraste, otras representaciones sociales dan cuenta de que, si bien algunas OCDS preponderantes mantienen una franca posición antigubernamental, diversos sectores persisten en reivindicar y revalorar su derecho a la 
transparente, libre, efectiva, no condicionada y no subalternizada intermediación pública, no en el área estatal, sino civil.

"El valor que tenemos:....Honestidad de caja registradora, nos contratan y hacemos el trabajo tal como se ofreció y lo esperábamos. Una práctica...en los noventa, era captar recursos y al final no hacer lo ofrecido...Eso nos parece deshonesto y no lo compartimos".

"Nuestros fundadores (a mediados de los ochenta) se dieron cuenta de que parte del origen de los problemas urbanos estaba en el sistema político,...Así hicimos campañas de opinión pública y loby en el congreso (con) una visión...de influencia en lo político, aunque (con la) misión general (de) promover la libertad de acción en todas las esferas..."

"...no fuimos ni somos progobierno, prooposición, ni propartido específico, sólo propartidos...No caemos en el trabajo social que legitima partidos, como en la Cuarta República".

Es importante señalar que, actualmente, presenciamos una tendencia al rebasamiento de la misión primigenia de algunas OCDS, especialmente coincidentes con intereses de medios de difusión masiva y con el protagonismo partidista antigubernamental. Ello, en circunstancias en que los esfuerzos del gobierno no han sido eficientes ni totalmente suficientes para establecer reglas claras -aún entre las que apoyan al proceso sociopolítico bolivariano- a los fines de sentar corresponsabilidades sobre la base de deberes y derechos, como bien lo enfoca la representación social siguiente:

"La corrupción de muchas es patente y ocurrió con el Fondo Único Social, cuyo millardiano presupuesto fue ejecu- tado mediante convenios con ong's, algunas creadas recientemente en condiciones que hicieron inviable la contraloría de los dineros que eran para los pobres. Se robaron más de dos mil millones de bolívares y la prensa le echó la culpa al gobierno. Como se quejaban de que la Cuarta República abusó de ellas, que no les pagaban a tiempo, que los trámites eran excesivos, etc., Chávez les creyó y cayó de ingenuo".

Lo anterior pareciera dar cuenta de una condición del Estado venezolano que debemos tener en cuenta para estudios de mayor profundidad. En este sentido -y sin que ello implique en modo alguno nuestra adscripción a las teorías de la confabulación y del poder suma ceroa dquiere relevancia la pregunta de si las fortalezas de las OCDS correlacionan inversamente con las debilidades del Estado o si las debilidades de aquéllas están implicadas en las fortalezas de éste.

A ello apunta la representación social de uno de nuestros entrevistados, para quien el gobierno se encuentra enfrentado al dilema siguiente:

“...delega(r) en ong's, en las cuales poco creé por la corrupción de muchas de ellas, o si ejecuta de manera directa a sabiendas de que su capacidad está estrangulada por los sindicatos y la cultura del tortuguismo, y se le hace difícil ejecutar y controlar la gestión de sus políticas".

Pero más allá de esta disyuntiva, a la anterior representación social subyace una imagen políticamente disminuida de las OCDS, a causa de una combinatoria de factores cruciales, antes enumerados. Entre éstos el cambio de las reglas del sistema político y, por lo tanto, de las formas de hacer política (cabildeo inclusi- 
ve); asimismo, la inviabilidad de constituir la macroesfera pública en un sector privado no lucrativo con corte de ong's, tal como algunos sectores esperaron que sucediera dentro del marco de las políticas neoliberales del decenio pasado.

Como consecuencia, el posicionamiento de espacios y la consolidación de otros que las OCDS pudieran haber ganado en el decenio anterior, pareciera que se han visto deprimidos.

"...ganaron espacios y conquistas importantes en los noventa pero están perdiéndolas dentro del marco de la centralización y concentración del poder".

"Uno de los muchos espacios que...no hemos ocupado es la organización de los consumidores, que no puede depender...ni del estado ni de las empresas".

"...se fue(ron) debilitando cuando algunas perdieron su perfil y se involucraron en la política cortoplacista y personalista".

Lo anterior coincide con la percepción de que, a inicios de 1999 comenzó a ser difundido un discurso que estimuló la creación de OCDS alternativas a las denominadas ong's, aunque muchas veces de manera no muy distinta a la convocatoria de la primera mitad de los noventa, para que -desde adentro y desde abajo, canalicen procesos de transformación social y autosustentabilidad popular.

"En Lara se ve más este deslinde, instancias de articulación que se generaron a inicios de los 90 , no son las mismas de hoy ni son de la misma tendencia ideológica...Ha habido cambios...en esa autopercepción neoliberaloide que aún se mantiene entre algunas ong's".
"En estos últimos años hay nuevas organizaciones como la nuestra, que se han propuesto objetivos más politizados de manera consciente...comprometidas con la autosustentabilidad de los procesos locales y populares".

Ello en circunstancias en que el estado venezolano muestra una tendencia a la rearticulación de los circuitos de acumulación de poder político, económico y simbólico y de cambios en la correlación de las fuerzas sociales.

\section{Consideraciones Finales}

Este trabajo revela la importancia de estudios sistematizados que buscan develar el heterogéneo universo de las organizaciones civiles de desarrollo social y las significaciones e imágenes que se producen y reproducen en sus realidades específicas.

Retomamos algunos aspectos importantes que se encuentran en el conjunto de las representaciones sociales producidas por nuestras sujetos de estudio, dejando abiertas algunas interrogantes que se develarán en la continuidad de esta investigación.

1. Debilidad del Estado, fortaleza de las organizaciones civiles de desarrollo social. Por lo general se parte de la imagen de un Estado y, más específicamente, del simple gobierno al que muchas reducen aquél, cuya debilidad es significada como fortaleza de las organizaciones civiles de desarrollo social. Entonces, ¿la fortaleza del estado es la debilidad de las organizaciones civiles de desarrollo social? $\mathrm{Si}$ el Estado venezolano se encuentra 
fraguando un proceso inédito de reconstitución con un alto componente de centralidad que se acompaña con un importante grado de protagonismo ciudadano, ¿significa que las organizaciones civiles de desarrollo social se encuentran fortalecidas como tales?, ¿están ganado o perdiendo espacios, autonomía?

2. Las estrategias de posicionamiento. Las organizaciones civiles de desarrollo social tienen estrategias de poder y tratan de conquistar poder, pero ¿qué tipo de poder se representan?, ¿a qué nivel de política -"chiquita" o "grande", dentro o fuera del régimen de partidos- y cuál es el justo papel que les corresponde desempeñar?, ¿cuál es la viabilidad de las organizaciones civiles de desarrollo social en la novel República Bolivariana de Venezuela, en donde las rearticulaciones de los circuitos de poder y de las fuerzas sociales podrían significar la constitución de nuevos actores que propongan hacer lo que ellas hacen 0 no están haciendo?

3. El nivel de educación y cultura política. Algunas organizaciones civiles de desarrollo social consideran como punto de partida de su papel de intermediación, el nivel educativo de sus beneficiarios y de sí mismas, representándose así que a partir de esto tendrán más éxito y fortaleza. Otras consideran la participación de las organizaciones populares sin tomar en cuenta dicho nivel, considerando más importante el conocimiento que ellas tengan de sus comunidades y de sus propias necesidades $y$, de esta manera, potenciar procesos de habilitación o facultamiento ciudadano.
4. La relación con el Estado. Las organizaciones civiles de desarrollo social se representan su relación con el estado mediante el financiamiento que el benefactor le otorga a la beneficiaria. Sin embargo, no pudimos captar una representación del reembolso, no en moneda sino en cuanto al desarrollo efectivo de los programa sociales. ¿Qué pasa con esta relación?, ¿es honesta o disfrazada?, ¿a partir de qué criterios se representan ésta?, ¿la relación es de aliados orgánicos, pragmático-utilitarios, dependencia recíproca o unidireccional?

5. El papel asignado a los beneficiarios. Las organizaciones civiles de desarrollo social permiten la incorporación de sus beneficiarios al desarrollo de los programas sólo en tanto consumidores de sus servicios. Piden autonomía y codecisión al Estado, pero bloquean la participación activa de sus beneficiarios. ¿De qué participación se trata y en qué se diferencian del Estado?

6. La producción de ciudadanía. Las organizaciones civiles de desarrollo social se representan como productoras de ciudadanía, sin embargo las estrategias utilizadas se basan en cursos de capacitación y asistencia técnica, autoestima y motivación al logro. ¿Es posible hablar de ciudadanía a alguien que carece de servicios básicos que le permitan satisfacer sus necesidades elementales?, ¿qué ciudadanía están produciendo las organizaciones civiles de desarrollo social: de primera, de segunda, parcial o integral?

Finalizamos estas consideraciones con varias preguntas: 
- ¿Cuán expresado se ve el estado venezolano en los impactos que las organizaciones civiles de desarrollo social vienen produciendo sobre la base de los convenios establecidos?

- ¿Qué alcance tienen dichos impactos, por cuánto tiempo son sostenibles sus efectos multiplicadores y cuáles son sus costos de oportunidad?

- ¿Cuán efectivo está siendo el estado venezolano en construir una plataforma institucional básica de definiciones conceptuales y operativas e instrumentos técnicos, políticos, financieros y administrativos que le permita construir las alianzas estratégicas con los actores que necesita, a los fines de construirle viabilidad y asegurarle coherencia y consistencia a una política de desarrollo social y de desarrollo local-nacional orgánica?

- Establecido un cierto perfil de las organizaciones civiles de desarrollo social, lo cual permitiría demarcar un cierto ámbito de sus límites y potencialidades más allá de las cuales podrían incurrir en ineficiencia y sobreponderaciones, ¿qué otro tipo de organizaciones de la sociedad civil podrían estar en capacidad de profundizar los logros obtenidos por aquéllas?

- ¿Estamos ante una disyuntiva o frente a un falso dilema?

\section{Bibliografía Citada}

Asamblea Legislativa del Estado Lara (1997), Ley de Planificación y Participación de la Sociedad Civil en la gestión pública del Estado Lara, Barquisimeto, Venezuela.
Barrantes, César (1997), El apoyo a la economía popular, ¿Hacia una política social orgánica de estado?, Editorial Tropykos/Faces-UCV, Caracas.

Barrantes, César (1998), Organizaciones civiles de desarrollo social, estado y economía popular en Venezuela, Investigación financiada por el Consejo de Desarrollo Científico y Humanístico de la Universidad Central de Venezuela, Trabajo de ascenso, Escuela de Trabajo Social, Universidad Central de Venezuela, Caracas.

Barrantes, César (1999), "Organizaciones de intermediación y estado. ¿Decentralización o publificación? La economía popular en Venezuela", en Revista Venezolana de Gerencia, No. 7, 1999 de la Universidad del Zulia, Maracaibo, Venezuela.

Bejarano, Ana María (1996), "Para repensar las relaciones estado, sociedad civil y régimen político. Una nueva mirada conceptual", en Revista Venezolana de Ciencias Económicas y Sociales, vol. 2, No. 2-3, abril-septiembre, Universidad Central de Venezuela, Caracas.

Bisbal, Marcelino; Nicodemo, Pasquale (1992), "La credibilidad de la democracia", en Revista SIC, año LV, No.542, marzo, Centro Gumilla, Caracas.

Cartaya, Vanessa (coorda., 1993), Alternativas no convencionales de prestación de servicios de seguridad social en el Área Metropolitana de Caracas. FEGS-ILDIS, Caracas.

Carvallo, Moisés (1999), "Los nuevos programas sociales: notas para un balance", en Álvarez, del Rosario, Robles (coords., 1999: 141-168).

Cisor (1997a), "El Polo asociativo y la sociedad civil: hacia una tipología-clasificación de las organizaciones de desarrollo social en Venezuela" (Alberto Grusón, 
Matilde Parra y Blas Regnault), Cisor, Caracas.

Cisor (1997b), Organizaciones de Venezuela. Cisor, Caracas.

Cordiplan (1995), Noveno Plan de la Nación, 1995-1999, Presidencia de la República de Venezuela, Caracas.

Cunill Grau, Nuria (1995), "La rearticulación de las relaciones estado-sociedad: en búsqueda de nuevos sentidos", en Reforma y Democracia, Revista del Clad, No. 4, Caracas.

Cunnil Grau, Nuria (1997), Repensando Io público a través de la sociedad. Nuevas formas de gestión pública y representación social, Clad-Nueva Sociedad, Caracas.

García, María Pilar (1991), Ambiente, Estado y Sociedad. Crisis y Conflictos Socioambientales en América Latina y Venezuela, Universidad Simón Bolívar, Centro de Estudios del Desarrollo, Universidad Central de Venezuela, Caracas.

García, María Pilar y Roa, Ernesto (1997), "La red de organizaciones sociales liberales y la democracia en Venezuela: potencialidades y limitaciones", en Cuadernos del CENDES, año 14, No. 35, mayo-agosto, págs. 55-80, Universidad Central de Venezuela, Caracas.

Gómez, Luis (1995), "Crisis de legitimidad e inestabilidad política en Venezuela", en Revista Venezolana de Economía y Ciencias Sociales, No. 2-3, págs. 103-164, Facultad de Ciencias Económicas y Sociales, Universidad Central de Venezuela, Caracas.

González, Franklin (1997), "A un año de la Agenda Venezuela. Evaluación de una ilusión", en Revista Venezolana de Análisis de Coyuntura, Universidad Central de Venezuela, vol. III, No. 2, págs. 185-219, Caracas.
González, Rosa Amelia (coorda., 1998), EI sector sin fines de lucro en Venezuela: Definiciones y clasificación", primer informe. lesa, marzo, Caracas.

Ibáñez, Tomás (1989), El conocimiento de la realidad social, Sendai, Barcelona, España.

Ibáñez, Tomás (1996a), "La construcción del conocimiento desde una perspectiva socioconstruccionista", en Montero (coord., 1996).

Ibáñez, Tomás (1996b), "Fluctuaciones conceptuales en torno a la posmodernidad y la sicología", Conferencias dictadas del 15 al 25 de noviembre de 1993, Facultad de Humanidades y Educación, Universidad Central de Venezuela, Comisión de Estudios de Posgrado, Caracas.

Lander, Edgardo (1995a), "Movimientos sociales urbanos, sociedad civil y nuevas formas de ciudadanía en Venezuela", en Revista Venezolana de Economía y Ciencias Sociales, No. 2-3, págs. 165-187, Universidad Central de Venezuela, y en Lander (1995b), Caracas.

Lander, Edgardo (1995b), Neoliberalismo, Sociedad Civil y Democracia. Ensayos sobre América Latina y Venezuela, Consejo de Desarrollo Científico y Humanístico, Universidad Central de Venezuela, Caracas.

López Maya, Margarita (1984), "Organizaciones asociativas de la Venezuela en transición (1900-1945)", en Cuadernos del Cendes, No. 4, segunda época, págs. 137-166, Universidad Central de Venezuela, Caracas.

López Maya, Margarita (1999a), "La protesta popular venezolana entre 1989 y 1993 (en el umbral del neoliberalismo)", en ella misma (Eda., 1999:211238). 
López Maya, Margarita (1999b), Lucha popular, democracia y liberalismo:protesta popular en América Latina en los años de ajuste, Cendes/Ceap/UCV/Editorial "Nueva Sociedad", Caracas.

Machado, Clemy (1997), "Las nuevas relaciones entre el estado y la sociedad civil en la Venezuela en transición: algunas experiencias", en Cuadernos del Cendes, año 14, No. 34, págs. 95126, Universidad Central de Venezuela, Caracas.

Magallanes, Rodolfo (1995) "Patrones de organización de la sociedad civil en Venezuela (cambios recientes)", Politeia, No. 18, págs. 233-265, Instituto de Estudios Políticos, Universidad Central de Venezuela, Caracas.

Magallanes, Rodolfo (1997), "Lo público y lo privado a finales de siglo. ¿Una distinción en desuso?", en Cuadernos del Cendes, Año 4, No. 36, segunda época, septiembre-diciembre de 1997, págs. 35-66, Centro de Estudios del Desarrollo, Universidad Central de Venezuela, Caracas.

Mato, Daniel (2000a), "Producción trasnacional y representaciones sociales y cambio social en tiempos de globalización", en Mato (coord. 2000a).

Mato, Daniel (2000b), Globalización, Cultura

y Cambio Social, Consejo Latinoamericano de Ciencias Sociales, Buenos Aires.
Mora Martínez, Martín (1998), "El modelo de las representaciones sociales de Serge Moscovici", Universidad de Guadalajara, México; Universitat Autònoma de Barcelona, España, Doctorat de Sicología Social, en línea: http://www.geocities.com/Paris/Rue/8759/.

Moscovici, Serge (1979), El sicoanálisis, su imagen y su público, Editorial Huemul, Buenos Aires.

Navarro, Juan Carlos (1994), Organizaciones de Participación Comunitaria. Una Aproximación a su Papel en la Prestación de Servicios Sociales a los Pobres en América Latina, Red de Centros de Investigación Económica Aplicada/Instituto de Estudios Superiores de Administración/Banco Interamericano de Desarrollo, Caracas.

Pulido, Mercedes (1999), "El impacto de los programas sociales. Balance y perspectivas", en Álvarez, del Rosario, Robles (coords., 1999: 131-139).

Salamanca (1999), "Protestas venezolanas en el segundo gobierno de Rafael Caldera: 1994-1997", en López (1999:239264).

Socsal (1998), Realidad y tendencias de las organizaciones de desarrollo social y su acción en Venezuela, mimeo, Caracas. 
López Maya, Margarita (1999b), Lucha popular, democracia y liberalismo:protesta popular en América Latina en los años de ajuste, Cendes/Ceap/UCV/Editorial "Nueva Sociedad", Caracas.

Machado, Clemy (1997), "Las nuevas relaciones entre el estado y la sociedad civil en la Venezuela en transición: algunas experiencias", en Cuadernos del Cendes, año 14, No. 34, págs. 95126, Universidad Central de Venezuela, Caracas.

Magallanes, Rodolfo (1995) "Patrones de organización de la sociedad civil en Venezuela (cambios recientes)", Politeia, No. 18, págs. 233-265, Instituto de Estudios Políticos, Universidad Central de Venezuela, Caracas.

Magallanes, Rodolfo (1997), "Lo público y lo privado a finales de siglo. ¿Una distinción en desuso?", en Cuadernos del Cendes, Año 4, No. 36, segunda época, septiembre-diciembre de 1997, págs. 35-66, Centro de Estudios del Desarrollo, Universidad Central de Venezuela, Caracas.

Mato, Daniel (2000a), "Producción trasnacional y representaciones sociales y cambio social en tiempos de globalización", en Mato (coord. 2000a).

Mato, Daniel (2000b), Globalización, Cultura

y Cambio Social, Consejo Latinoamericano de Ciencias Sociales, Buenos Aires.
Mora Martínez, Martín (1998), "El modelo de las representaciones sociales de Serge Moscovici", Universidad de Guadalajara, México; Universitat Autònoma de Barcelona, España, Doctorat de Sicología Social, en línea: http://www.geocities.com/Paris/Rue/8759/.

Moscovici, Serge (1979), El sicoanálisis, su imagen y su público, Editorial Huemul, Buenos Aires.

Navarro, Juan Carlos (1994), Organizaciones de Participación Comunitaria. Una Aproximación a su Papel en la Prestación de Servicios Sociales a los Pobres en América Latina, Red de Centros de Investigación Económica Aplicada/Instituto de Estudios Superiores de Administración/Banco Interamericano de Desarrollo, Caracas.

Pulido, Mercedes (1999), "El impacto de los programas sociales. Balance y perspectivas", en Álvarez, del Rosario, Robles (coords., 1999: 131-139).

Salamanca (1999), "Protestas venezolanas en el segundo gobierno de Rafael Caldera: 1994-1997", en López (1999:239264).

Socsal (1998), Realidad y tendencias de las organizaciones de desarrollo social y su acción en Venezuela, mimeo, Caracas. 
López Maya, Margarita (1999b), Lucha popular, democracia y liberalismo:protesta popular en América Latina en los años de ajuste, Cendes/Ceap/UCV/Editorial "Nueva Sociedad", Caracas.

Machado, Clemy (1997), "Las nuevas relaciones entre el estado y la sociedad civil en la Venezuela en transición: algunas experiencias", en Cuadernos del Cendes, año 14, No. 34, págs. 95126, Universidad Central de Venezuela, Caracas.

Magallanes, Rodolfo (1995) "Patrones de organización de la sociedad civil en Venezuela (cambios recientes)", Politeia, No. 18, págs. 233-265, Instituto de Estudios Políticos, Universidad Central de Venezuela, Caracas.

Magallanes, Rodolfo (1997), "Lo público y lo privado a finales de siglo. ¿Una distinción en desuso?", en Cuadernos del Cendes, Año 4, No. 36, segunda época, septiembre-diciembre de 1997, págs. 35-66, Centro de Estudios del Desarrollo, Universidad Central de Venezuela, Caracas.

Mato, Daniel (2000a), "Producción trasnacional y representaciones sociales y cambio social en tiempos de globalización", en Mato (coord. 2000a).

Mato, Daniel (2000b), Globalización, Cultura

y Cambio Social, Consejo Latinoamericano de Ciencias Sociales, Buenos Aires.
Mora Martínez, Martín (1998), "El modelo de las representaciones sociales de Serge Moscovici", Universidad de Guadalajara, México; Universitat Autònoma de Barcelona, España, Doctorat de Sicología Social, en línea: http://www.geocities.com/Paris/Rue/8759/.

Moscovici, Serge (1979), El sicoanálisis, su imagen y su público, Editorial Huemul, Buenos Aires.

Navarro, Juan Carlos (1994), Organizaciones de Participación Comunitaria. Una Aproximación a su Papel en la Prestación de Servicios Sociales a los Pobres en América Latina, Red de Centros de Investigación Económica Aplicada/Instituto de Estudios Superiores de Administración/Banco Interamericano de Desarrollo, Caracas.

Pulido, Mercedes (1999), "El impacto de los programas sociales. Balance y perspectivas", en Álvarez, del Rosario, Robles (coords., 1999: 131-139).

Salamanca (1999), "Protestas venezolanas en el segundo gobierno de Rafael Caldera: 1994-1997", en López (1999:239264).

Socsal (1998), Realidad y tendencias de las organizaciones de desarrollo social y su acción en Venezuela, mimeo, Caracas. 